\title{
Virtual Cancer Care During the COVID-19 Pandemic and Beyond: A Call for Evaluation
}

Oren Hannun Levine ${ }^{1,2^{*}}$, MSc, MD; Michael McGillion ${ }^{3 *}, \mathrm{RN}$, DPhil; Mark Levine ${ }^{1,2^{*}}$, MSc, MD

\author{
${ }^{1}$ Department of Oncology, McMaster University, Hamilton, ON, Canada \\ ${ }^{2}$ Hamilton Health Sciences - Juravinski Cancer Centre, Hamilton, ON, Canada \\ ${ }^{3}$ School of Nursing, McMaster University, Hamilton, ON, Canada \\ *all authors contributed equally
}

\section{Corresponding Author:}

Mark Levine, MSc, MD

Department of Oncology

McMaster University

Room 104, G Wing

711 Concession Street

Hamilton, ON, L8V 1C3

Canada

Phone: 19055272299 ext 42176

Email: mlevine@mcmaster.ca

\begin{abstract}
The interplay of virtual care and cancer care in the context of the COVID-19 pandemic is unique and unprecedented. Patients with cancer are at increased risk of SARS-CoV-2 infection and have worse outcomes than patients with COVID-19 who do not have cancer. Virtual care has been introduced quickly and extemporaneously in cancer treatment centers worldwide to maintain COVID-19-free zones. The outbreak of COVID-19 in a cancer center could have devastating consequences. The virtual care intervention that was first used in our cancer center, as well as many others, was a landline telephone in an office or clinic that connected a clinician with a patient. There is a lack of virtual care evaluation from the perspectives of patients and oncology health care providers. A number of factors for assessing oncology care delivered through a virtual care intervention have been described, including patient rapport, frailty, delicate conversations, team-based care, resident education, patient safety, technical effectiveness, privacy, operational effectiveness, and resource utilization. These factors are organized according to the National Quality Forum framework for the assessment of telehealth in oncology. This includes the following 4 domains of assessing outcomes: experience, access to care, effectiveness, and financial impact or cost. In terms of virtual care and oncology, the pandemic has opened the door to change. The lessons learned during the initial period of the pandemic have given rise to opportunities for the evolution of long-term virtual care. The opportunity to evaluate and improve virtual care should be seized upon.
\end{abstract}

(JMIR Cancer 2020;6(2):e24222) doi: $\underline{10.2196 / 24222}$

\section{KEYWORDS}

care; patient-physician relationship; patient-centered care; oncology care delivery; virtual visits; telehealth; virtual care; cancer; oncology; evaluation; COVID-19

\section{Introduction}

The COVID-19 pandemic has catapulted virtual care into the forefront of oncology practice [1-7]. The interplay of virtual care and cancer care in the context of the pandemic is unique and unprecedented [1-7]. Patients with cancer are at increased risk of SARS-CoV-2 infection because of immunosuppression $[8,9]$ and frequent visits to cancer centers for therapy, which potentially increases their risk of contracting and transmitting
COVID-19 [9]. Furthermore, the outcomes of patients with cancer and COVID-19 are likely worse than those of patients with COVID-19 who do not have cancer [10-14]. The introduction of virtual care during the onset of the pandemic was an emergency strategy for maintaining cancer centers as COVID-19-free zones to avoid any potential interruption in treatments.

In this commentary, virtual care is defined as an interaction between clinicians and patients that occurs remotely through 
communication or information technologies with the aim of facilitating or maximizing the quality and effectiveness of patient care $[15,16]$. During the onset of the pandemic, a landline telephone in an office or clinic was first used in our cancer center to conduct consultations and follow-up assessments, share test results with patients and families, and have delicate and difficult conversations. The use of telephone landlines was our first immediate option for remote care during the pandemic crisis. This experience stimulated our thoughts on virtual care and our need to increase capacity in this regard. Initially, there was limited video connectivity in cancer centers. However, this is now changing, and the pandemic has allowed for virtual care approaches to evolve.

Virtual care has been introduced quickly and has featured extemporaneous implementation under time pressure [1-7]. It is anticipated that there will be pressure to continue virtual care in oncology because of its efficiency and potential to cut costs [17]. However, there is a lack of virtual care evaluation from the perspectives of patients and oncology health care providers. Herein, we consider the impact of the virtualization of oncology practices with respect to a number of factors. Based on our recent experience with virtual care, albeit mostly telephone-based care, we highlight opportunities to evaluate models of care in oncology practices that incorporate any virtual technology. The factors that we consider are organized according to the National Quality Form framework for the assessment of telehealth in oncology. This includes the following 4 domains of assessing outcomes: experience, access to care, effectiveness, and financial impact or cost [18] (Table 1).

Table 1. National Quality Forum telehealth measurement framework.

\begin{tabular}{|c|c|c|c|c|}
\hline \multirow[t]{2}{*}{ Factors } & \multicolumn{4}{|l|}{ Domains $^{\mathrm{a}}$} \\
\hline & Access to care & Financial impact or cost & Experience & Effectiveness \\
\hline Patient rapport & & & + & \\
\hline Patient frailty & & & + & \\
\hline Delicate conversations & & & + & \\
\hline Multidisciplinary care & + & & & \\
\hline Role of the nurse & + & & & \\
\hline Resident education & & & & + \\
\hline Patient safety & & & + & + \\
\hline Technical effectiveness & & & & + \\
\hline Privacy & & & & + \\
\hline Operational effectiveness & & + & & + \\
\hline Resource utilization & & + & & \\
\hline
\end{tabular}

${ }^{\mathrm{a}}$ The domain related to a factor.

\section{Experience}

\section{Patient Rapport}

Establishing a strong rapport with patients is important for building trust [19]. A patient's first visit to a cancer center is often the most important for building strong clinician-patient relationships [19]. Diagnoses, prognoses, and treatment options are usually addressed in the first consultation visit. Furthermore, the physical examination can impact the care plan, and thorough assessments may contribute to a sense of trust with medical care. With remote care, it can be more challenging to establish patient rapport. Strong rapport is helpful for identifying when a patient's status has changed (eg, cancer spread) and providing compassionate care $[19,20]$. Methods for optimizing the sense of connectedness between patients and care providers during virtual care requires further study.

\section{Patient Frailty}

Many patients with cancer are older adults who have other comorbid medical illnesses. Frailty is not an illness; it is a syndrome that combines the effects of natural aging with the outcomes of multiple long-term conditions, such as the loss of fitness and reserves [21]. Chemotherapy is often associated with toxicity, which can sometimes be life-threatening, and toxicity tends to increase with age. However, there are older patients whose physical conditions are robust. It is important to be able to assess the frailty of the patient to avoid the risk of excessive toxicity and undertreatment. The reliability of remote frailty assessments requires exploration.

\section{Delicate Conversations}

Bad news conversations can be very difficult during remote care, especially over the phone [22,23]. Even when using video-based technology, it may not be possible to pick up on body language and visual cues to gauge how a patient is receiving information. The parameters of video-based communication can limit direct eye contact and leave room for miscommunication and the indeterminacy of one's intent [24]. Thus, it remains unclear whether visits scheduled for potentially sensitive conversations should be done virtually or in person. If such conversations are done in person during the time of a pandemic, the patient must arrive alone for what may be a 
difficult and anxiety-provoking experience. Assessing patient experience may help define a reasonable standard.

\section{Access to Care}

\section{Multidisciplinary Care}

Multidisciplinary clinics are an important part of specialized oncology care at any major cancer center [25]. Surgical, medical, and radiation oncologists assess patients together in order to make a treatment recommendation. Usually, this requires multiple people in 1 room and violates physical distancing recommendations. Virtual technology allows multiple specialists to interact with a patient at the same time, but it can be cumbersome and logistically challenging. Patient and care provider satisfaction is an important measure for ensuring that multidisciplinary care is sustainable in a virtual model.

\section{Role of the Nurse}

In many cancer centers, the model of nursing is a shared-care model between oncologists and nurses. Nurses have many responsibilities regarding patient care, including symptom assessment, health education, and triaging calls regarding treatment toxicity and the psychologic, emotional, and social aspects of care [26]. There is potential for the nurse's role to be marginalized due to virtual care. We see a need for the in-depth evaluation of the impact of virtual care on the supportive and relational aspects of nursing work.

\section{Effectiveness}

\section{Resident Education}

Another challenge is incorporating medical student and postgraduate resident education into virtual practice. Traditionally, in clinics, a resident enters a patient examining room to take an illness history and perform a physical examination. Afterward, they leave the room and confer with the staff oncologist, which is an opportunity for on-the-fly teaching. Upon returning to the patient together with the staff oncologist, there is a chance for bedside teaching. This process cannot be performed with remote care. Recently, there has been a shift toward competency-based residency education, which emphasizes direct observation and feedback [27,28]. Video calls may allow for the observation of a resident's communication skills. However, whether this is sufficient to establish a trainee's competence for clinical practice requires validation.

\section{Patient Safety}

It is routine for a patient to be weighed at every visit. Weight can be an important clue for determining changes in health status and the need to change drug dosing. Standardized symptom assessments are completed before visiting the clinician. These assessments also serve as a screen for important changes in health status. However, the uptake of online symptom screening has been inconsistent. Without these early warning signs, are patients more likely to experience toxicity? Health services research could help elucidate this question.

\section{Technical Effectiveness}

It is important to keep in mind that many patients do not have access to video calling software, high-speed internet, or email [29-31]. Furthermore, the patient's prior experience with technology may affect the success of virtual encounters [29-31]. Occasionally, sound quality, language barriers, and hearing impairment make it difficult to determine if information has been understood correctly. Other barriers to virtual communication include somnolence and confusion from chemotherapy, supportive medications (eg, narcotics), or advanced cancer [32].

\section{Privacy}

Patients and care providers must trust that the information being transmitted during care is private and secure $[30,31,33]$. When health care practices are conducted virtually and all information is transferred electronically, the situation becomes more complex. There remains much to be learned about implementing and scaling virtual care in oncology per the Hospital Level 7 integration standards for seamless and cybersecure hospital-to-home connection [34]. The best practices for implementing virtual care models that measurably preserve patients' and families' privacy and ensure the security of data throughout the virtual care process are paramount [34].

\section{Financial Impact or Cost}

\section{Operational Effectiveness}

Patient convenience and clinical service-related satisfaction may be enhanced through virtual care, as costly parking fees and lengthy periods in waiting rooms can be avoided. Physician reimbursement was an issue during the beginning of the pandemic due to the rapid implementation of virtual care in oncology, but this has been addressed [33]. From the clinician's perspective, follow-up visits may be shorter, allowing for more patient assessments. However, if a patient is unavailable, is time lost through repeated attempts to contact that patient? Whether virtual care in oncology is more efficient than in-person care remains unknown, but this should be studied $[33,35]$.

\section{Resource Utilization}

If patients perceive a lack of access to cancer centers when urgent in-person assessments are needed, they may resort to visiting the emergency department for symptom complaints or treatment toxicity. Administrative data should be scrutinized to assess the impact of virtual care on acute care resource utilization [35].

\section{Conclusion}

In terms of virtual care and oncology, the COVID-19 pandemic has opened the door to change. The lessons learned during the initial period of the pandemic have given rise to opportunities for the evolution of long-term virtual care. It would be unfortunate not to learn from our experiences through thoughtful and scholarly assessment. Assessment measures should span the areas of experience, access to care, effectiveness, and financial impact or cost. The opportunity to evaluate and improve virtual care should be seized upon. 


\section{Conflicts of Interest}

None declared.

\section{References}

1. Mullangi S, Schleicher SM, Aviki EM. Innovation in Cancer Care Delivery in the Era of COVID-19. JCO Oncol Pract 2020 Nov;16(11):718-719. [doi: 10.1200/OP.20.00336] [Medline: $\underline{32552318}$ ]

2. Mulvey TM, Jacobson JO. COVID-19 and Cancer Care: Ensuring Safety While Transforming Care Delivery. J Clin Oncol 2020 Oct 01;38(28):3248-3251. [doi: 10.1200/JCO.20.01474] [Medline: 32749939]

3. The Lancet Oncology. COVID-19: global consequences for oncology. Lancet Oncol 2020 Apr;21(4):467 [FREE Full text] [doi: 10.1016/S1470-2045(20)30175-3] [Medline: 32240603]

4. van de Haar J, Hoes LR, Coles CE, Seamon K, Fröhling S, Jäger D, et al. Caring for patients with cancer in the COVID-19 era. Nat Med 2020 May;26(5):665-671. [doi: 10.1038/s41591-020-0874-8] [Medline: 32405058]

5. Cinar P, Cox J, Kamal A, Bickel K, Krzyzanowska M, Armitage J, et al. Oncology Care Delivery in the COVID-19 Pandemic: An Opportunity to Study Innovations and Outcomes. JCO Oncol Pract 2020 Aug;16(8):431-434. [doi: 10.1200/OP.20.00326] [Medline: 32463764]

6. Segelov E, Underhill C, Prenen H, Karapetis C, Jackson C, Nott L, et al. Practical Considerations for Treating Patients With Cancer in the COVID-19 Pandemic. JCO Oncol Pract 2020 Aug;16(8):467-482. [doi: 10.1200/OP.20.00229] [Medline: $\underline{32401686]}$

7. Schrag D, Hershman DL, Basch E. Oncology Practice During the COVID-19 Pandemic. JAMA 2020 May 26;323(20):2005-2006. [doi: 10.1001/jama.2020.6236] [Medline: $\underline{32282023}$ ]

8. Dai M, Liu D, Liu M, Zhou F, Li G, Chen Z, et al. Patients with Cancer Appear More Vulnerable to SARS-CoV-2: A Multicenter Study during the COVID-19 Outbreak. Cancer Discov 2020 Jun;10(6):783-791 [FREE Full text] [doi: 10.1158/2159-8290.CD-20-0422] [Medline: 32345594]

9. London JW, Fazio-Eynullayeva E, Palchuk MB, Sankey P, McNair C. Effects of the COVID-19 Pandemic on Cancer-Related Patient Encounters. JCO Clin Cancer Inform 2020 Jul;4:657-665 [FREE Full text] [doi: 10.1200/CCI.20.00068] [Medline: $\underline{32716647]}$

10. Liang W, Guan W, Chen R, Wang W, Li J, Xu K, et al. Cancer patients in SARS-CoV-2 infection: a nationwide analysis in China. Lancet Oncol 2020 Mar;21(3):335-337 [FREE Full text] [doi: 10.1016/S1470-2045(20)30096-6] [Medline: $\underline{32066541]}$

11. Wang D, Hu B, Hu C, Zhu F, Liu X, Zhang J, et al. Clinical Characteristics of 138 Hospitalized Patients With 2019 Novel Coronavirus-Infected Pneumonia in Wuhan, China. JAMA 2020 Mar 17;323(11):1061-1069 [FREE Full text] [doi: 10.1001/jama.2020.1585] [Medline: $\underline{32031570]}$

12. Miyashita H, Mikami T, Chopra N, Yamada T, Chernyavsky S, Rizk D, et al. Do patients with cancer have a poorer prognosis of COVID-19? An experience in New York City. Ann Oncol 2020 Aug;31(8):1088-1089 [FREE Full text] [doi: 10.1016/j.annonc.2020.04.006] [Medline: $\underline{32330541]}$

13. Mehta V, Goel S, Kabarriti R, Cole D, Goldfinger M, Acuna-Villaorduna A, et al. Case Fatality Rate of Cancer Patients with COVID-19 in a New York Hospital System. Cancer Discov 2020 Jul;10(7):935-941 [FREE Full text] [doi: 10.1158/2159-8290.CD-20-0516] [Medline: 32357994]

14. Kuderer NM, Choueiri TK, Shah DP, Shyr Y, Rubinstein SM, Rivera DR, COVID-19 and Cancer Consortium. Clinical impact of COVID-19 on patients with cancer (CCC19): a cohort study. Lancet 2020 Jun 20;395(10241):1907-1918 [FREE Full text] [doi: 10.1016/S0140-6736(20)31187-9] [Medline: $\underline{32473681]}$

15. Schwamm LH, Erskine A, Licurse A. A digital embrace to blunt the curve of COVID19 pandemic. NPJ Digit Med 2020 May 04;3:64 [FREE Full text] [doi: 10.1038/s41746-020-0279-6] [Medline: 32377575]

16. Canadian Medical Association. Virtual Care In Canada: Discussion paper. CMA Health Summit. URL: https://www.cma.ca/ sites/default/files/pdf/News/Virtual Care discussionpaper v2EN.pdf [accessed 2020-11-13]

17. Meti N, Rossos PG, Cheung MC, Singh S. Virtual Cancer Care During and Beyond the COVID-19 Pandemic: We Need to Get It Right. JCO Oncol Pract 2020 Sep;16(9):527-529. [doi: 10.1200/OP.20.00281] [Medline: 32401684]

18. Rising KL, Ward MM, Goldwater JC, Bhagianadh D, Hollander JE. Framework to Advance Oncology-Related Telehealth. JCO Clin Cancer Inform 2018 Dec;2:1-11 [FREE Full text] [doi: 10.1200/CCI.17.00156] [Medline: 30652582]

19. American Society of Clinical Oncology. Communication: What Do Patients Want and Need? J Oncol Pract 2008 Sep;4(5):249-253 [FREE Full text] [doi: 10.1200/JOP.0856501] [Medline: 29452527]

20. Journey Mapping in Cancer Care Maps. BC Patient Safety \& Quality Council. 2019 Feb 01. URL: https://bcpsqc.ca/resource/ journey-mapping-in-cancer-care-maps [accessed 2020-11-13]

21. Pal SK, Katheria V, Hurria A. Evaluating the older patient with cancer: understanding frailty and the geriatric assessment. CA Cancer J Clin 2010;60(2):120-132 [FREE Full text] [doi: 10.3322/caac.20059] [Medline: 20173172]

22. Fallowfield L, Jenkins V. Communicating sad, bad, and difficult news in medicine. Lancet 2004 Jan 24;363(9405):312-319. [doi: 10.1016/S0140-6736(03)15392-5] [Medline: 14751707 ] 
23. Baile WF, Buckman R, Lenzi R, Glober G, Beale EA, Kudelka AP. SPIKES-A six-step protocol for delivering bad news: application to the patient with cancer. Oncologist 2000;5(4):302-311 [FREE Full text] [doi: 10.1634/theoncologist.5-4-302] [Medline: 10964998]

24. Adams RD. Virtual meeting 101: Body language tips for Zoom, Teams, and life. TechRepublic. 2020 Jul 10. URL: https:/ /www.techrepublic.com/article/virtual-meeting-101-body-language-tips-for-zoom-teams-and-life [accessed 2020-11-13]

25. Selby P, Popescu R, Lawler M, Butcher H, Costa A. The Value and Future Developments of Multidisciplinary Team Cancer Care. Am Soc Clin Oncol Educ Book 2019 Jan;39:332-340 [FREE Full text] [doi: 10.1200/EDBK 236857] [Medline: 31099640]

26. Rieger PT, Yarbro CH. Role of the Oncology Nurse. In: Kufe DW, Pollock RE, Weichselbaum RR, Bast RCJ, Gansler TS, Holland JF, et al, editors. Kufe DW, Pollock RE, Weichselbaum RR. editors. Holland-Frei Cancer Medicine. 6th edition. Hamilton (ON): BC Decker; 2003.

27. Harris KA, Nousiainen MT, Reznick R. Competency-based resident education-The Canadian perspective. Surgery 2020 Apr;167(4):681-684. [doi: 10.1016/j.surg.2019.06.033] [Medline: 31431292]

28. Frank JR, Snell L, Englander R, Holmboe ES, ICBME Collaborators. Implementing competency-based medical education: Moving forward. Med Teach 2017 Jun;39(6):568-573. [doi: 10.1080/0142159X.2017.1315069] [Medline: 28598743]

29. Virtual Care: Recommendations for Scaling Up Virtual Medical Services. Canadian Medical Association. 2020 Feb. URL: https://www.cma.ca/sites/default/files/pdf/virtual-care/ReportoftheVirtualCareTaskForce.pdf [accessed 2020-11-13]

30. Anthony BJ. Use of Telemedicine and Virtual Care for Remote Treatment in Response to COVID-19 Pandemic. J Med Syst 2020 Jun 15;44(7):132 [FREE Full text] [doi: 10.1007/s10916-020-01596-5] [Medline: 32542571]

31. Kruse CS, Karem P, Shifflett K, Vegi L, Ravi K, Brooks M. Evaluating barriers to adopting telemedicine worldwide: A systematic review. J Telemed Telecare 2018 Jan;24(1):4-12 [FREE Full text] [doi: 10.1177/1357633X16674087] [Medline: 29320966]

32. Ozguroglu M, Sari O, Turna H. Devastating effects of chemotherapy: deafness and acute renal failure in a patient with epithelial ovarian cancer. Int J Gynecol Cancer 2006;16 Suppl 1:394-396. [doi: 10.1111/j.1525-1438.2006.00214.x] [Medline: 16515631]

33. Kichloo A, Albosta M, Dettloff K, Wani F, El-Amir Z, Singh J, et al. Telemedicine, the current COVID-19 pandemic and the future: a narrative review and perspectives moving forward in the USA. Fam Med Community Health 2020 Aug;8(3) [FREE Full text] [doi: 10.1136/fmch-2020-000530] [Medline: 32816942]

34. Moorman BA, Cockle RA. Medical device integration using mobile telecommunications infrastructure. Biomed Instrum Technol 2013;47(3):224-232. [doi: 10.2345/0899-8205-47.3.224] [Medline: 23692108]

35. Nord G, Rising KL, Band RA, Carr BG, Hollander JE. On-demand synchronous audio video telemedicine visits are cost effective. Am J Emerg Med 2019 May;37(5):890-894. [doi: 10.1016/j.ajem.2018.08.017] [Medline: $\underline{\text { 30100333] }}$

Edited by G Eysenbach; submitted 10.09.20; peer-reviewed by F Holl, Z Su; comments to author 29.09.20; revised version received
08.11.20; accepted 10.11.20; published 24.11.20
Please cite as:
Levine OH, McGillion M, Levine M
Virtual Cancer Care During the COVID-19 Pandemic and Beyond: A Call for Evaluation
JMIR Cancer $2020 ; 6(2):$ :e24222
URL: $\underline{\text { http://cancer.jmir.org/2020/2/e24222/ }}$
doi: $10.2196 / 24222$
PMID: $\underline{33180741}$

(C) Oren Hannun Levine, Michael McGillion, Mark Levine. Originally published in JMIR Cancer (http://cancer.jmir.org), 24.11.2020. This is an open-access article distributed under the terms of the Creative Commons Attribution License (https://creativecommons.org/licenses/by/4.0/), which permits unrestricted use, distribution, and reproduction in any medium, provided the original work, first published in JMIR Cancer, is properly cited. The complete bibliographic information, a link to the original publication on http://cancer.jmir.org/, as well as this copyright and license information must be included. 